Article

\title{
Moisture Performance of Energy-Efficient and Conventional Wood-Frame Wall Assemblies in a Mixed-Humid Climate
}

\section{Samuel V. Glass ${ }^{1, *}$, Vladimir Kochkin ${ }^{2}$, S. Craig Drumheller ${ }^{3}$ and Lance Barta ${ }^{2}$}

1 Building and Fire Sciences, U.S. Forest Service Forest Products Laboratory, 1 Gifford Pinchot Dr., Madison, WI 53726, USA

2 Applied Engineering, Home Innovation Research Labs, 400 Prince George's Blvd., Upper Marlboro, MD 20774, USA; E-Mails: vkochkin@homeinnovation.com (V.K.); 1barta@homeinnovation.com (L.B.)

3 Construction Codes and Standards, National Association of Home Builders, 1201 15th Street NW, Washington, DC 20005, USA; E-Mail: cdrumheller@nahb.org

* Author to whom correspondence should be addressed; E-Mail: svglass@fs.fed.us;

Tel.: +1-608-231-9401; Fax: +1-608-231-9303.

Academic Editor: Fitsum Tariku

Received: 27 April 2015 / Accepted: 25 June 2015 / Published: 1 July 2015

\begin{abstract}
Long-term moisture performance is a critical consideration for design and construction of building envelopes in energy-efficient buildings, yet field measurements of moisture characteristics for highly insulated wood-frame walls in mixed-humid climates are lacking. Temperature, relative humidity, and moisture content of wood framing and oriented strand board (OSB) structural panel sheathing were measured over a period from mid-November 2011 through March 2013 in both north- and south-facing orientations in test structures near Washington, DC, USA. Wall configurations varied in exterior cladding, water-resistive barrier, level of cavity insulation, presence of exterior continuous insulation, and interior vapor retarder. The combination of high interior humidity and high vapor permeance of painted gypsum board led to significant moisture accumulation in OSB sheathing during winter in walls without a vapor retarder. In contrast, wintertime moisture accumulation was not significant with an interior kraft vapor retarder. Extruded polystyrene exterior insulation had a predictable effect on wall cavity temperature but a marginal impact on OSB moisture content in walls with vinyl siding and interior kraft vapor retarder. Hygrothermal simulations approximately captured the timing of seasonal
\end{abstract}


changes in OSB moisture content, differences between north- and south-facing walls, and differences between walls with and without an interior kraft vapor retarder.

Keywords: moisture performance; hygrothermal performance; durability; building envelope; wood-frame; vapor retarder; continuous insulation; hygrothermal simulation

\section{Introduction}

The long-term moisture performance of exterior wall assemblies is a critical consideration for energy-efficient building envelopes. Designers and builders have many options in contemporary wood-frame wall construction for selecting materials such as exterior cladding, insulation, and vapor retarders. Consumer demand has grown for energy-efficient, high-performance buildings. Recent changes to model energy codes, particularly the 2012 International Energy Conservation Code (IECC) [1], have increased minimum insulation levels and tightened air leakage requirements for all light-frame wood wall systems (relative to the 2009 IECC [2]), and continuous exterior insulation may be an option or a requirement, depending on climate zone. With moisture performance increasingly becoming a concern and a design consideration, practical guidance is needed that will minimize the risk of moisture performance and durability problems in wood-frame buildings. Research-based design guidance is particularly needed as various industry groups are advocating specific wall design solutions based on incomplete information.

Climate characteristics must be considered in relation to wall system moisture performance. Mixed-humid climates, as defined by Lstiburek [3] (and adopted by the U.S. Department of Energy [4]), have the following characteristics: (1) more than $0.5 \mathrm{~m}$ (20 in.) of annual precipitation; (2) 3000 or fewer annual heating degree days (base $18{ }^{\circ} \mathrm{C}$ ) (5400 or fewer annual heating degree days (base $\left.65^{\circ} \mathrm{F}\right)$ ); and (3) an average monthly winter temperature below $7{ }^{\circ} \mathrm{C}\left(45^{\circ} \mathrm{F}\right)$. The mixed-humid climate typically results in moisture migration from the building interior to exterior during winter and from the exterior to interior during summer. The moisture response of the building envelope depends on the local environmental conditions, such as wind-driven rain, solar radiation, temperature, and humidity, as well as interior moisture loads.

The need for vapor diffusion control depends on climate; in mixed-humid climates, outward vapor diffusion during winter is not as significant as in cold climates, so higher interior vapor permeance is recommended in mixed-humid climates, which also allows inward drying during summer [3]. The International Residential Code (IRC) [5], for example, does not require an interior vapor retarder in Climate Zone 4A. This is in accord with work by Karagiozis et al. [6], who evaluated vapor retarder recommendations for wood-frame wall systems using a calibrated hygrothermal model for a number of North American locations, including several mixed-humid climate locations. Wood-frame walls were simulated with either brick veneer or vinyl siding, building paper, OSB, glass fiber cavity insulation, and interior gypsum board with latex primer and paint. Four vapor retarder options were evaluated: polyethylene sheet, asphalt-coated kraft paper (a common facing on batt insulation), polyamide sheet (so-called "smart" vapor retarder, having vapor permeance that is dependent on relative humidity), and no vapor retarder. The vapor permeance of the interior latex primer and paint coating was selected as $460 \mathrm{ng} /\left(\mathrm{Pa} \cdot \mathrm{s} \cdot \mathrm{m}^{2}\right)$ (8 perms). In Climate Zone 4A locations, walls with polyamide film gave the best 
performance, followed by walls with kraft vapor retarder. For walls with no vapor retarder, simulated OSB moisture content (MC) did not exceed 16\% for more than 30 days when interior humidity levels were low but did reach $18 \%-25 \% \mathrm{MC}$ in some cases for more than 30 days when interior humidity levels were high. Although the study did not evaluate potential for mold growth, it can be noted that wood moisture content exceeding $20 \%$ has traditionally been considered potentially at risk for decay [7].

Measured values of the vapor permeance of gypsum board with interior latex primer and paint vary. Values listed for paint films and for gypsum board with one coat of primer and two coats of latex paint are less than $570 \mathrm{ng} /\left(\mathrm{Pa} \cdot \mathrm{s} \cdot \mathrm{m}^{2}\right)$ (10 perms) below 60\% relative humidity [8,9]. The IRC [5] considers latex paint a Class III vapor retarder, having a dry cup vapor permeance in the range from 57 to $570 \mathrm{ng} /\left(\mathrm{Pa} \cdot \mathrm{s} \cdot \mathrm{m}^{2}\right)$ (1 to 10 perms). However, several studies have measured considerably higher values [10-12]. This suggests that interior gypsum board with latex primer and paint might not reliably provide sufficient vapor diffusion resistance to avoid moisture accumulation, particularly when interior humidity levels are high. The emphasis here on vapor diffusion should not be taken in isolation: Air leakage has long been recognized as a more important mechanism for water vapor transfer than vapor diffusion [13-15]. Nonetheless, moisture control strategies need to address both mechanisms.

Although moisture performance of conventional wood-frame building envelopes has been studied extensively in North America since the 1940s [16], such research on wall assemblies with increased insulation levels is limited to the past five years. For this article, "conventional" walls are considered to have cavity insulation of $140 \mathrm{~mm}$ depth (nominal $2 \times 6$ ) in cold climates and $89 \mathrm{~mm}$ depth (nominal $2 \times 4$ ) in mixed-humid climates; "energy-efficient" walls have higher insulation levels than conventional walls. Various methods of constructing energy-efficient walls have been in use since the 1970s, such as double-stud and truss walls; more recent variations include wood-frame walls with continuous exterior rigid insulation. Monitoring studies investigating moisture conditions in energy-efficient wood-frame wall assemblies have recently been conducted in cold climates [17-22] and marine climates [23]. In some cases, studies examined the response to controlled levels of air leakage or controlled wetting by liquid water. A recent study [24] monitored energy-efficient walls in 22 houses located in six different climate zones. Before this study, data were lacking for energy-efficient walls in mixed-humid climates. Prior moisture research on conventional wood-frame walls in mixed-humid climates is minimal [16], comprising a survey of occupied houses in the 1960s and a few exploratory studies in the 1940s and 1970s. More recently, conventional wood-frame wall assemblies with a range of cladding materials have been monitored in test structures near Washington, DC [12,25,26]; the present study builds on this work.

The project described here involves monitoring of exterior wall assemblies with specific design characteristics installed in two test structures on the campus of Home Innovation Research Labs, located in Upper Marlboro, MD, approximately $30 \mathrm{~km}$ east of Washington, DC (IECC Climate Zone 4A). The overarching goal of this research is to identify design and construction practices for durable exterior wood-frame walls in a mixed-humid climate. Six configurations of energy efficient walls are studied: four with exterior rigid foam insulation installed over oriented strand board (OSB) structural panel sheathing, with the study variables including different levels of cavity insulation and types of water-resistive barrier; and two with $38 \mathrm{~mm} \times 140 \mathrm{~mm}$ (nominal $2 \times 6$ ) framing with different interior vapor retarders (kraft-facing vs. gypsum with interior paint only). In addition, six conventional $38 \mathrm{~mm} \times 89 \mathrm{~mm}$ (nominal $2 \times 4$ ) wood-frame wall systems with varying cladding materials including 
stucco, manufactured stone, vinyl siding, brick, and fiber cement siding are monitored to provide continuity with previous work $[12,25,26]$. Specifically, the impact of the interior vapor retarder on the performance of these conventional systems is evaluated under elevated levels of interior relative humidity. Cedar siding is added in the present monitoring phase to expand the range of cladding systems. Additionally, the study evaluates the capability of hygrothermal modeling software to predict the moisture performance of various wall systems under known climatic conditions.

\section{Experimental Methods}

\subsection{Description of Test Structures}

Two outdoor test structures (depicted in Figure 1) have been in use since 2008 on the campus of Home Innovation Research Labs (formerly NAHB Research Center), located in Upper Marlboro, Maryland, approximately $30 \mathrm{~km}$ east of Washington, DC (IECC Climate Zone 4A). Each structure has a nominal footprint of $2.4 \mathrm{~m} \times 14.6 \mathrm{~m}(8 \mathrm{ft} \times 48 \mathrm{ft})$, and each long side features five pairs of $2.4 \mathrm{~m}(8 \mathrm{ft})$ wide by $2.7 \mathrm{~m}(9 \mathrm{ft})$ high bays for installation of test wall sections. The structures are oriented with the long axis aligned east to west. Wall assemblies are tested in pairs with each wall configuration in north- and south-facing orientation.

In both structures the underside of the floor joists is approximately $0.75 \mathrm{~m}(2.5 \mathrm{ft})$ above grade and insulated with $160 \mathrm{~mm}$ (6.25 in.) glass fiber batt insulation. The roof is shingled on 4/12 pitch trusses (slope of $18.4^{\circ}$ ) and insulated with $230 \mathrm{~mm}$ (9 in.) glass fiber batt insulation at the attic-ceiling interface. The roof overhang is limited to a $100 \mathrm{~mm}$ (4 in.) gutter leading to appreciable exposure of test walls to the elements. One door is installed on the east-facing end wall of each structure with a window on the west-facing end wall.

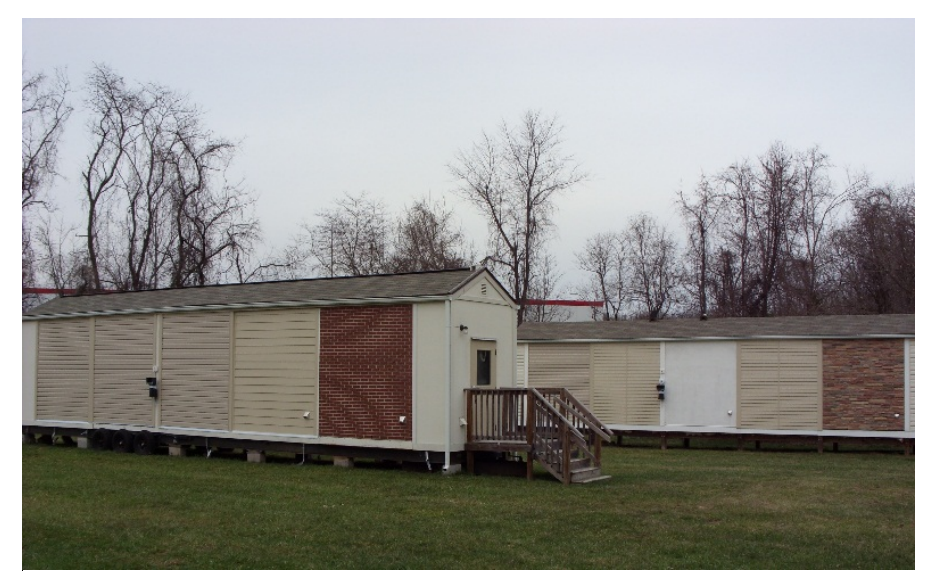

Figure 1. Test structures showing south-facing wall assemblies.

\subsection{Interior and Exterior Conditions}

Interior temperatures within the test structures were maintained using portable air conditioners during summer, in the range $25.6-26.7^{\circ} \mathrm{C}\left(78-80^{\circ} \mathrm{F}\right)$, and using electrical resistance heating during winter, in the range $21.1-22.2^{\circ} \mathrm{C}\left(70-72{ }^{\circ} \mathrm{F}\right)$. Each test structure included six type-T thermocouples and two probes measuring temperature and relative humidity. 
Interior relative humidity $(\mathrm{RH})$ was maintained using humidifiers during the heating season at a moving set point calculated as a function of the daily average exterior temperature (Figure 2a), an adaptation of the Simplified Method for Indoor Design Humidity in ASHRAE Standard 160-2009 [27]. The probes used to monitor interior temperature and $\mathrm{RH}$ included capacitance-type humidity sensors, accurate within $2 \%$ from $0 \%$ to $98 \% \mathrm{RH}$. Target and measured interior $\mathrm{RH}$ levels are depicted in Figure $2 \mathrm{~b}$. The average interior relative humidity over the two winters was $55 \% \mathrm{RH}$. This value is considerably higher than typical levels in residential buildings in this climate. By comparison, winter average values in five houses in Maryland and Delaware (same climate zone 4A) were between 31\% and 48\% [24]. The winter average in 10 houses in Knoxville, Tennessee (also 4A), was 40\% (with a standard deviation of $8 \%$ ) [28]. The rationale for maintaining such indoor RH levels was to stress the wall assemblies with a high interior moisture load; differences in moisture conditions between wall configurations may not be evident with low or typical interior humidity levels [29]. The interior RH levels from April to September were considerably lower than target values because the humidifiers were turned off; interior RH levels were then dependent on exterior vapor pressure, air exchange rates, and dehumidification as a result of air-conditioner operation. The difference between interior and exterior vapor pressures is shown in Figure 2c. The vapor drive is outward during the heating season and inward during the cooling season.

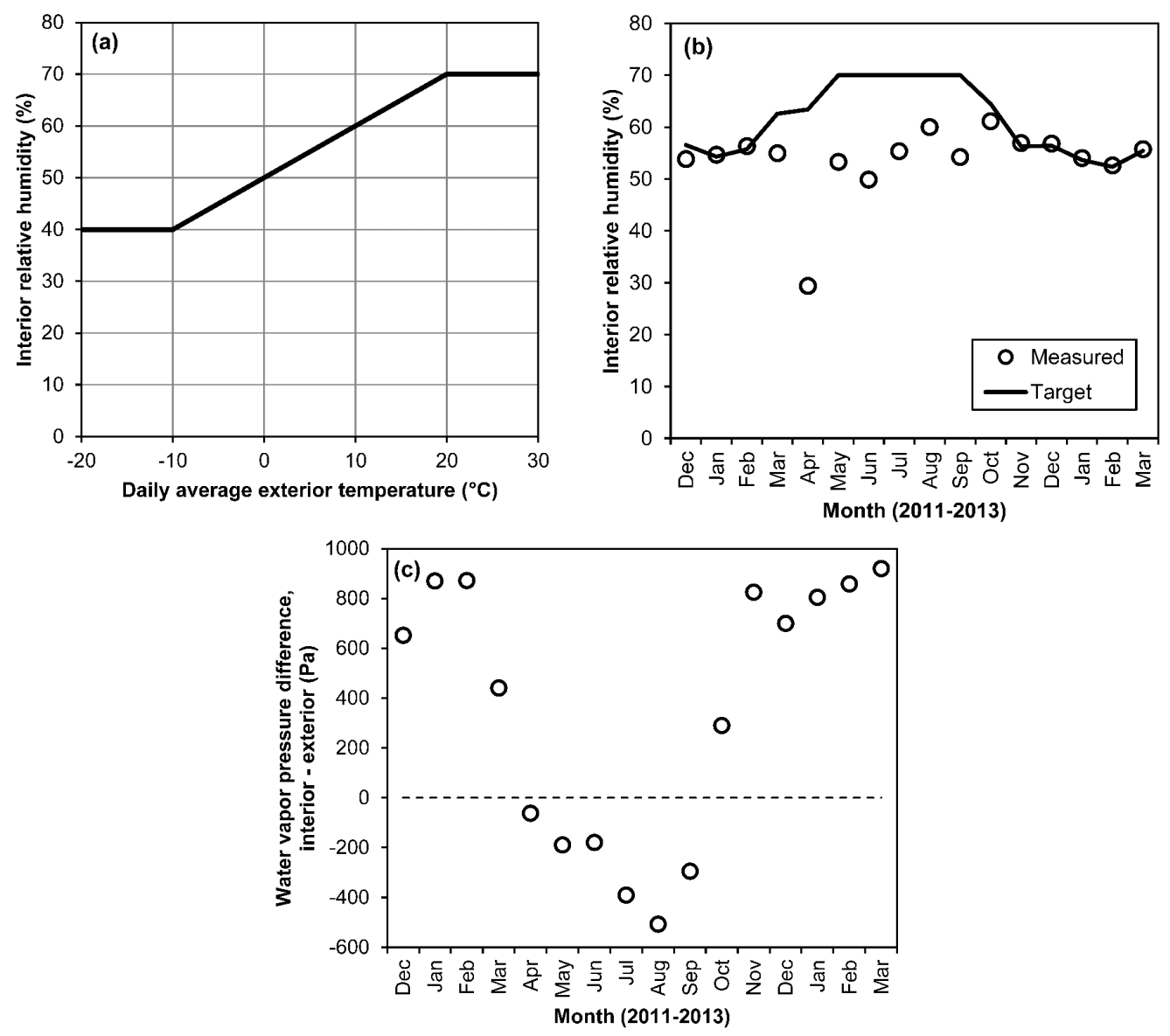

Figure 2. (a) Target interior relative humidity as a function of outdoor temperature; (b) Target and measured monthly average interior relative humidity over the monitoring period; (c) Difference between monthly average interior and exterior water vapor pressure over the monitoring period. 
A weather station was mounted on the roof of one test structure. The station included an anemometer to measure wind speed and direction, a temperature and humidity sensor, a tipping-bucket rain gauge, and a horizontally installed spectral pyranometer to measure solar radiation. Vertically positioned spectral pyranometers were installed on the north and south walls of the test hut to better understand the conditions at the wall surface.

Exterior temperature and precipitation measured onsite are depicted in Figures 3 and 4, and are compared with 30-year average values from Andrews Air Force Base, located roughly $15 \mathrm{~km}$ (10 mi) from the site. All months were warmer than the historical average except November 2012 and March 2013 (Figure 3). Although precipitation measured onsite varied significantly from historical average values on a monthly basis (Figure 4a), cumulative precipitation measured over the monitoring period (1565 mm (61.6 in.)) was similar to the sum of historical monthly average data (1511 mm (59.5 in.); Figure 4b). Rainfall in the wake of Hurricane Sandy contributed to the anomaly in October 2012. However, OSB moisture content measurements reported below did not indicate any definitive increase following the high rainfall.

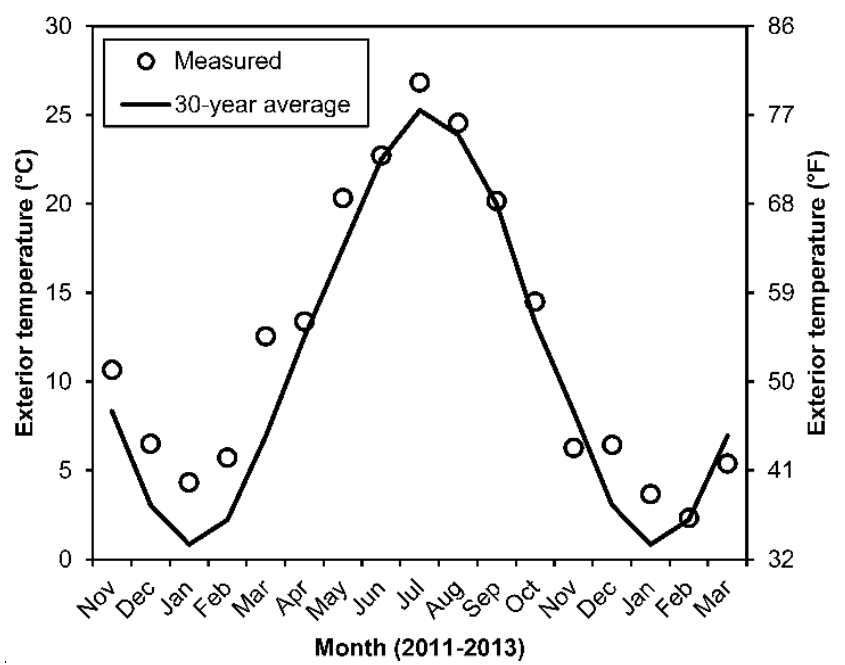

Figure 3. Monthly average exterior temperature measured onsite compared with 30-year average values.
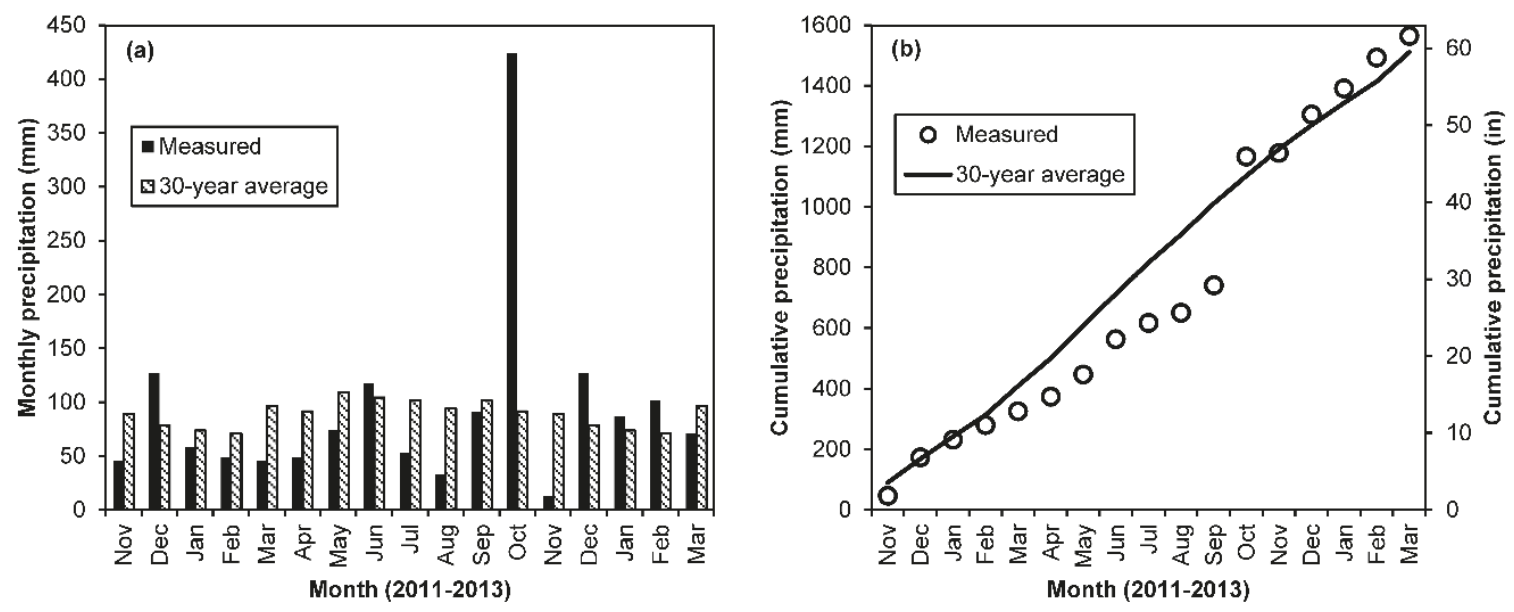

Figure 4. Precipitation measured onsite compared with 30-year average values: (a) Monthly total precipitation; (b) Cumulative precipitation over the monitoring period. 


\subsection{Wall Configurations}

Nine primary wall configurations were monitored (Table 1). Each assembly was duplicated in north and south orientations. Cladding systems included manufactured stone veneer, stucco, cedar siding, vinyl siding, brick veneer, and fiber cement siding; these are described in further detail below. Each primary wall configuration included a subcategory designated in the matrix by (a) or (b) to study the specific effect of one of the assembly features: cladding, water-resistive barrier (WRB), or interior vapor retarder. Wall assemblies were constructed with either $38 \mathrm{~mm} \times 89 \mathrm{~mm}$ (nominal $2 \times 4$ ) or $38 \mathrm{~mm} \times 140 \mathrm{~mm}$ (nominal $2 \times 6$ ) softwood lumber framing, in all cases with studs spaced $0.4 \mathrm{~m}$ (16 in.) on center and with single bottom plates and double top plates. All assemblies had structural panel sheathing consisting of $11 \mathrm{~mm}$ (7/16 in.) oriented strand board (OSB) on the exterior of the framing and $12.5 \mathrm{~mm}(1 / 2 \mathrm{in}$.) interior gypsum board, which was finished with a latex primer and two rolled-on coats of latex paint. Cavity insulation was glass fiber batt insulation in all cases, either with kraft facing or no facing; nominal thermal resistance was $2.3 \mathrm{~m}^{2} \cdot \mathrm{K} / \mathrm{W}\left(13 \mathrm{~h} \cdot \mathrm{ft}^{2} \cdot{ }^{\circ} \mathrm{F} / \mathrm{Btu}\right)$ for $89 \mathrm{~mm}$ (3.5 in.) thickness and $3.7 \mathrm{~m}^{2} \cdot \mathrm{K} / \mathrm{W}\left(21 \mathrm{~h} \cdot \mathrm{ft}^{2} \cdot{ }^{\circ} \mathrm{F} / \mathrm{Btu}\right)$ for $140 \mathrm{~mm}(5.5 \mathrm{in}$.$) thickness.$

Table 1. Test wall configurations.

\begin{tabular}{|c|c|c|c|c|c|}
\hline Label & Cladding & Exterior $\mathbf{C I}^{\mathbf{a}}$ & $W B^{b}$ & $\begin{array}{l}\text { Cavity } \\
\text { Depth }\end{array}$ & $\begin{array}{c}\text { Vapor } \\
\text { Retarder } \\
\end{array}$ \\
\hline $\begin{array}{ll}1 & \mathrm{a} \\
& \mathrm{b}\end{array}$ & Manufactured stone veneer & None & 2 layers \#15 felt & $89 \mathrm{~mm}$ & $\begin{array}{l}\text { Kraft facing } \\
\text { None }\end{array}$ \\
\hline $\begin{array}{l}\mathrm{a} \\
\mathrm{b}\end{array}$ & Portland cement stucco & None & 2 layers \#15 felt & $89 \mathrm{~mm}$ & $\begin{array}{c}\text { Kraft facing } \\
\text { None }\end{array}$ \\
\hline $\begin{array}{l}\mathrm{a} \\
\mathrm{b}\end{array}$ & $\begin{array}{c}\text { Solid cedar siding }{ }^{\mathrm{c}} \\
\text { Finger-jointed cedar siding }\end{array}$ & None & Corrugated SBPO $^{d}$ & $89 \mathrm{~mm}$ & Kraft facing \\
\hline $\begin{array}{l}\mathrm{a} \\
\mathrm{b}\end{array}$ & Vinyl siding & None & Conventional SBPO & $89 \mathrm{~mm}$ & $\begin{array}{c}\text { Kraft facing } \\
\text { None }\end{array}$ \\
\hline $\begin{array}{l}\mathrm{a} \\
\mathrm{b}\end{array}$ & Brick veneer ${ }^{\mathrm{e}}$ & None & Conventional SBPO & $89 \mathrm{~mm}$ & $\begin{array}{c}\text { Kraft facing } \\
\text { None }\end{array}$ \\
\hline $\begin{array}{l}\mathrm{a} \\
\mathrm{b}\end{array}$ & Fiber cement siding & None & Conventional SBPO & $89 \mathrm{~mm}$ & $\begin{array}{c}\text { Kraft facing } \\
\text { None }\end{array}$ \\
\hline $\begin{array}{l}\mathrm{a} \\
\mathrm{b}\end{array}$ & Vinyl siding & XPS $^{f}$ & $\begin{array}{l}\text { Corrugated SBPO } \\
\text { Taped XPS joints }\end{array}$ & $140 \mathrm{~mm}$ & Kraft facing \\
\hline $\begin{array}{l}\mathrm{a} \\
\mathrm{b}\end{array}$ & Vinyl siding & None & Conventional SBPO & $140 \mathrm{~mm}$ & $\begin{array}{c}\text { Kraft facing } \\
\text { None }\end{array}$ \\
\hline $\begin{array}{l}\mathrm{a} \\
\mathrm{b}\end{array}$ & Vinyl siding & XPS & $\begin{array}{c}\text { Corrugated SBPO } \\
\text { Taped XPS } \\
\end{array}$ & $89 \mathrm{~mm}$ & Kraft facing \\
\hline
\end{tabular}

Wall sections were separated by structural posts. On the exterior, the posts were covered with trim pieces to separate the different cladding systems (Figure 1). On the interior, gypsum board was installed with two sheets per wall section and one vertical taped seam. The gypsum board was caulked 
to the posts at each side and to the beam at the top edge. The bottom edge of the gypsum board was raised about $13 \mathrm{~mm}(1 / 2 \mathrm{in}$.) from the floor and not caulked or sealed, as is typical in common practice.

Manufactured stone veneer was cast concrete composed of Portland cement, aggregate, and pigments. Type S mortar mix was used for the scratch coat and grout. The stone was darker in color than the other claddings with the exception of brick veneer. The thickness of the stone varied between $25 \mathrm{~mm}$ (1 in.) and $67 \mathrm{~mm}$ (2.6 in.).

The stucco cladding was constructed with a Portland cement-based material that was designed to be both a scratch and finish coat. Final stucco thickness varied between $13 \mathrm{~mm}(1 / 2 \mathrm{in}$.) and $16 \mathrm{~mm}(5 / 8 \mathrm{in}$.). The Portland cement-based stucco was placed over ASTM D226 compliant [30] No. 15 felt and wire lath. The felt was stapled to the sheathing with $9.5 \mathrm{~mm}$ (3/8 in.) length and $25 \mathrm{~mm}$ (1 in.) crown staples; the wire lath was stapled using $12.7 \mathrm{~mm}(1 / 2 \mathrm{in}$.) crown and $19 \mathrm{~mm}$ (3/4 in.) length staples at $0.4 \mathrm{~m}$ (16 in.) on center.

The stucco-clad wall assembly was not constructed according to Section R703.6.3 of the 2009 IRC [5], which requires two layers of Grade D paper. However, it did have two layers of ASTM D 226 [30] Type 1 felt (No. 15 felt paper). The two materials differ primarily in vapor permeance: Grade D paper has a permeance in excess of $570 \mathrm{ng} /\left(\mathrm{Pa} \cdot \mathrm{s} \cdot \mathrm{m}^{2}\right)(10$ perms $)$, whereas No. 15 felt usually has a permeance of around $290 \mathrm{ng} /\left(\mathrm{Pa} \cdot \mathrm{s} \cdot \mathrm{m}^{2}\right)(5 \mathrm{perms})$. The felt used in the test, however, had a wet cup permeance of over $740 \mathrm{ng} /\left(\mathrm{Pa} \cdot \mathrm{s} \cdot \mathrm{m}^{2}\right)$ (13 perms). Some jurisdictions have amended Section R703.6.3 to include No. 15 felt as being acceptable under Portland cement exterior claddings. With this construction, the inner layer of felt functions as the drainage plane while the outer layer bonds to the stucco and thus is unable to function effectively as a drainage plane.

The cedar siding was $150 \mathrm{~mm}$ (6 in.) factory-primed planks attached to $19 \mathrm{~mm}(3 / 4 \mathrm{in}$.) thick by $38 \mathrm{~mm}$ (1.5 in.) wide vertical furring strips over the WRB. It is noted that the wall specimens were inset into the Test Hut such that there was no ventilation opening at the top or bottom of the cladding interface. The cedar siding was finished with two coats of acrylic flat paint. All site-cut edges were hand-primed prior to installation with latex primer. Siding planks were hand-nailed using stainless steel ring-shank nails (the edge nails were installed into pre-drilled holes). The $150 \mathrm{~mm}$ (6 in.) planks were overlapped by $32 \mathrm{~mm}$ (1.25 in.). Every second row of siding included a butt joint that was not caulked. Flashing was used only below the starter strip, and caulking was placed only on the vertical trim. This exterior cladding was subdivided into two halves: finger jointed planks and solid planks.

Vinyl siding was chosen for comparison because it is the most frequently installed cladding on new single-family houses in the U.S. [31]. Furthermore, due to its non-absorptive properties, its performance was expected to contrast with the absorptive cladding systems investigated on the other wall panels. The siding in Walls 4 and 8 was installed directly over a single layer of spun-bonded polyolefin (SBPO) WRB, representative of common vinyl siding installation practices in the United States. In Walls 7 and 9, the siding was nailed through the exterior extruded polystyrene (XPS) rigid foam insulation into the framing members. For configurations $7 \mathrm{a}$ and 9a, a corrugated ("drainage") house wrap was installed between the OSB sheathing and XPS insulation. For configurations $7 b$ and $9 b$, house wrap was not installed and the exterior XPS joints were taped to provide a drainage plane.

The brick veneer wall was constructed with a $25 \mathrm{~mm}$ (1 in.) air cavity behind the brick. A $13 \mathrm{~mm}$ (1/2 in.) slot at the top of the wall allowed the air space to vent into the attic. The nominal $100 \mathrm{~mm}$ (4 in.) bed depth brick was laid in Type $\mathrm{N}$ masonry cement mortar. Flashing was installed under the 
first course of brick, and open head joint weep holes were installed at $0.6 \mathrm{~m}$ (24 in.) on center immediately above the flashing.

Factory-primed $150 \mathrm{~mm}$ (6 in.) fiber cement planks were installed directly over a single layer of SBPO WRB with face nails into the framing (no furring strips or ventilation openings). Only the vertical trim was caulked. The siding was finished with two coats of latex primer and acrylic latex semi-gloss exterior paint.

\subsection{Laboratory Material Property Measurements}

Laboratory tests were conducted to measure water vapor permeance and density of the materials used in construction of the test wall sections. The measured properties were also used as inputs for hygrothermal modeling (Section 4). All materials were taken from the same batch of the product that was used to construct wall assemblies. Test methods for water vapor transmission included the desiccant method (dry cup) and the water method (wet cup) of ASTM E96 [32]. For both methods, the environmental chamber was set at $23{ }^{\circ} \mathrm{C}\left(73{ }^{\circ} \mathrm{F}\right)$ and $50 \% \mathrm{RH}$. Specimens were cut to $180 \mathrm{~mm} \times 180 \mathrm{~mm}$ ( 7 in. $\times 7$ in.); edges were sealed with foil tape and then sealed to a metal dish with wax. Three specimens of each material were tested. Density of each specimen was determined gravimetrically with volume calculated from measured dimensions [33].

Measured property values (Table 2) for most materials were in general concurrence with published values [8,9]. However, our measured vapor permeance of gypsum board with one coat of primer and two coats of latex paint are substantially higher than the values listed by ASHRAE [8] for paint films, or by Kumaran et al. [9] for gypsum board with one coat of primer and two coats of latex paint. Our measured permeance is also considerably higher than the value assumed by the IRC [5] of less than $570 \mathrm{ng} /\left(\mathrm{Pa} \cdot \mathrm{s} \cdot \mathrm{m}^{2}\right)(10 \mathrm{perms})$. This study is not, however, the first to measure higher values [10,11]. Our measured values are similar to those reported by Drumheller and Carll [12]. For asphalt-coated kraft paper, the observed increase in permeance from dry cup to wet cup is consistent with literature values, and the measured values are intermediate between those of Gatland [34] and Burch et al. [35]. Literature data for permeance of OSB, while spanning a considerable range, generally exhibit an increase in vapor permeance with increasing $\mathrm{RH}$ [36]; however, the opposite trend is observed in the measured dry cup and wet cup values here. The reason for this anomaly is unknown.

Table 2. Measured material properties.

\begin{tabular}{|c|c|c|c|c|}
\hline \multirow{2}{*}{ Material } & \multirow{2}{*}{$\begin{array}{l}\text { Thickness, } \\
\text { mm (in.) }\end{array}$} & \multirow{2}{*}{$\begin{array}{c}\text { Density, } \\
\mathrm{kg} / \mathrm{m}^{3}\left(\mathrm{lb} / \mathbf{f t}^{3}\right)\end{array}$} & \multicolumn{2}{|c|}{ Vapor Permeance, $\mathrm{ng} /\left(\mathrm{Pa} \cdot \mathbf{s} \cdot \mathrm{m}^{2}\right)($ perms $)$} \\
\hline & & & Dry Cup & Wet Cup \\
\hline Interior gypsum board & $12.4(0.489)$ & $500(31)$ & $2800(49)$ & $2600(45)$ \\
\hline $\begin{array}{l}\text { Interior gypsum board, one coat } \\
\text { primer and two coats latex paint }\end{array}$ & $12.5(0.493)$ & - & $2000(35)$ & $2000(35)$ \\
\hline Asphalt-coated kraft paper & $0.2(0.007)$ & $580(36)$ & $33(0.6)$ & $60(1.0)$ \\
\hline Oriented strand board & $11.0(0.435)$ & $680(42)$ & $110(2.0)$ & $80(1.4)$ \\
\hline Conventional spun-bonded polyolefin & $0.1(0.004)$ & $540(34)$ & $3000(52)$ & $2500(44)$ \\
\hline Corrugated spun-bonded polyolefin & $0.1(0.004)$ & $690(43)$ & $3000(53)$ & $2600(45)$ \\
\hline Extruded polystyrene & $24.9(0.979)$ & $27(1.7)$ & $61(1.1)$ & $57(1.0)$ \\
\hline Cedar & $4.4(0.173)$ & $336(21)$ & $120(2.1)$ & $570(10)$ \\
\hline Cedar, one coat primer and two coats paint & $4.6(0.182)$ & - & $35(0.6)$ & $190(3.2)$ \\
\hline
\end{tabular}




\subsection{Wall Moisture Content Measurements}

Each wall section had about 40 wireless sensors installed (Figure 5) that measured temperature, relative humidity, and wood moisture content at programmable time intervals (set to $30 \mathrm{~min}$ ) [12]. Each sensor includes two $50 \mathrm{~mm}$ (2 in.) uninsulated stainless steel screws that secure it to wood framing or OSB sheathing. The screws penetrate the wood member by $10 \mathrm{~mm}(0.4 \mathrm{in}$.) to obtain an electrical conductance reading related to substrate moisture content. The sensors have a moisture content measurement range (initially calibrated to Douglas fir) of $7 \%$ to $40 \% \mathrm{MC}$; a temperature range of $-40{ }^{\circ} \mathrm{C}$ to $85{ }^{\circ} \mathrm{C}\left(-40{ }^{\circ} \mathrm{F}\right.$ to $\left.185{ }^{\circ} \mathrm{F}\right)$, and a relative humidity range of $0 \%$ to $100 \%$. Data were transmitted wirelessly from the sensors every $30 \mathrm{~min}$ to a local gateway that periodically transmitted the data by Internet to a server maintained by the sensor manufacturer.

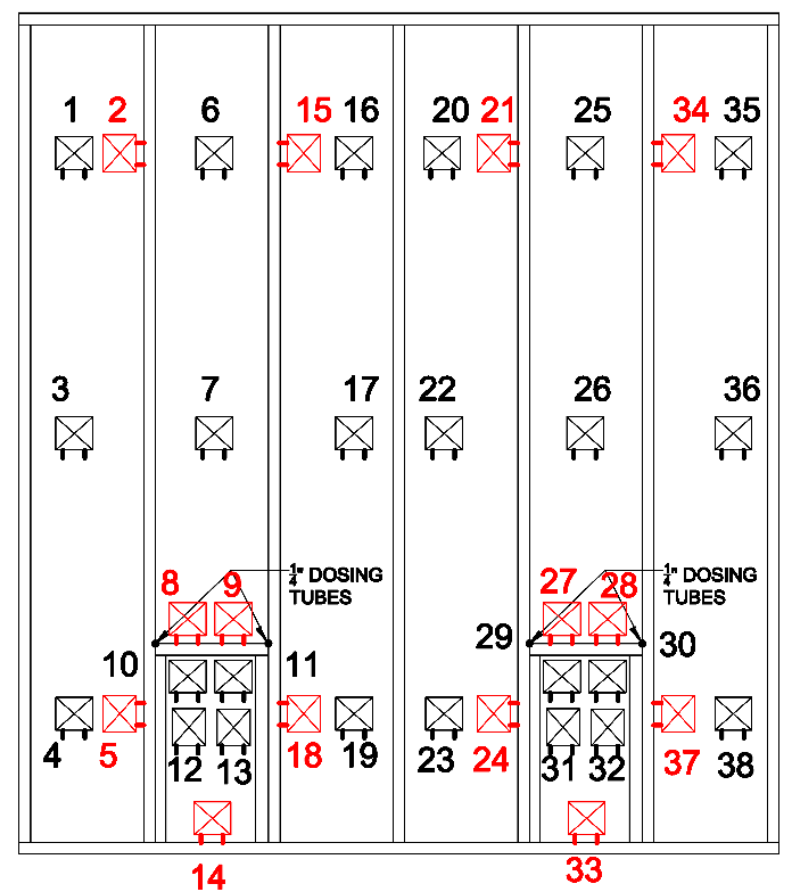

Figure 5. Typical sensor layout for $2.4 \mathrm{~m}(8 \mathrm{ft})$ wide by $2.7 \mathrm{~m}(9 \mathrm{ft})$ high wall section.

The sensor accuracy for temperature was $\pm 0.4^{\circ} \mathrm{C}\left( \pm 0.7^{\circ} \mathrm{F}\right)$ and for relative humidity was $\pm 3.5 \% \mathrm{RH}$. All moisture content readings were gravimetrically calibrated to wood framing and OSB (inclusive of resin mass) at room temperature. For OSB the maximum moisture content the sensors could read was about $25 \% \mathrm{MC}$. The calibration resulted in corrected sensor readings with a measurement uncertainty of about $\pm 2 \% \mathrm{MC}$ at room temperature. The manufacturer provided temperature compensation of the conductance readings obtained from the screw electrodes based on Douglas fir (temperature compensation for OSB is not known). The temperature reading that was used for compensation was, however, taken at a location within the sensor housing separated from the screw tips by roughly $35 \mathrm{~mm}$ (1.4 in.). Cavity insulation was installed over the sensor such that there was an air pocket between the sensor and the OSB sheathing. For conductance readings taken in sheathing, the temperature compensation may have been less than ideal. For comparison, a temperature offset of $6{ }^{\circ} \mathrm{C}$ $\left(10^{\circ} \mathrm{F}\right)$ would translate into a moisture content offset typically of less than $1 \% \mathrm{MC}$ for Douglas fir [37]. The air pockets between sensors and OSB sheathing may also have permitted air convection. 


\section{Experimental Results and Discussion}

\subsection{Effects of Kraft Vapor Retarder and Wall Orientation on OSB Moisture Performance}

OSB moisture content is plotted in Figure 6 for wall configurations with and without a kraft vapor retarder (i.e., batt insulation with and without kraft facing) for north and south orientations. The absence of the kraft facing corresponds with significant moisture accumulation, with wintertime OSB moisture contents near $25 \%$ for all six north-facing wall assemblies without kraft facing. Moisture levels may have exceeded $25 \% \mathrm{MC}$, which is approximately the fiber saturation point of OSB, but any levels greater than $25 \% \mathrm{MC}$ were recorded as being $25 \% \mathrm{MC}$. In contrast, wintertime OSB moisture contents in north-facing walls with kraft facing remained below $15 \% \mathrm{MC}$ with the exception of walls clad with manufactured stone veneer and stucco, which reached 16\%-18\% MC. As mentioned previously, rainfall in October 2012 was unusually high in the wake of Hurricane Sandy. However, OSB moisture content measurements do not indicate an increase that can be definitively attributed to rain. Walls without kraft facing generally show an increase, but this is likely a result of interior vapor, as walls with kraft facing generally do not change significantly.

For the south exposure, only the wall with stucco cladding (Wall 2) showed MC levels similar to the north exposure, though the $2 \times 4$ wall with vinyl siding (Wall 4) peaked at a comparable level for a short time in the second winter. This performance is consistent with outward moisture migration during winter that was slowed down by the stucco cladding for Wall 2. The remaining assemblies in the south exposure stayed close to or below 20\% MC. All wall assemblies, with and without a kraft vapor retarder, dried out rapidly over the spring months to levels below 15\% MC. This was likely a result of increasing temperatures and the considerable drop in interior $\mathrm{RH}$ in April once humidifiers were turned off (Figure 2b).

The observed behavior for walls without kraft facing should be evaluated in light of three factors. First, the interior relative humidity levels were set to represent a conservative upper value (Section 2.2). Second, the vapor permeance of primed and painted interior gypsum board was measured at $2000 \mathrm{ng} /\left(\mathrm{Pa} \cdot \mathrm{s} \cdot \mathrm{m}^{2}\right)$ (35 perms), considerably higher than some literature values (Section 2.4) and the IRC [5] classification as a Class III vapor retarder (vapor permeance less than $570 \mathrm{ng} /\left(\mathrm{Pa} \cdot \mathrm{s} \cdot \mathrm{m}^{2}\right)$ (10 perms)). Finally, there were no air-sealing measures implemented at the bottom of the interior gypsum board, and the potential for water vapor transfer by air leakage into the wall cavities was possibly greater where kraft facing was not installed. The kraft facing is not an air barrier but might retard airflow. The air permeance of the various wall sections was not tested, so conclusions cannot be drawn about the magnitude of vapor transfer by air leakage versus diffusion in these test walls.

The observed behavior of walls without kraft facing should also be compared with field monitoring of similar walls in five houses in the same climate zone [24]. Winter average interior RH levels were between $31 \%$ and $48 \%$ in these houses, compared with an average of $55 \% \mathrm{RH}$ in the test structures (Section 2.2). The walls in these houses had $2 \times 6$ framing, nominal R-23 blown glass fiber cavity insulation, and no vapor retarder other than interior paint. The average winter peak OSB moisture content was below $16 \%$; the vast majority of sensors were below $18 \%$, with only a few sensors peaking above $20 \%$ MC. However, there was not a clear trend between interior RH and wintertime 
OSB moisture content. It is possible that the interior paint used in these houses had a lower vapor permeance than that measured in this study.

Relative humidity levels measured in the cavities of the same wall sections (with and without kraft-facing) are depicted in Figure 7. These RH levels were measured approximately $25 \mathrm{~mm}(1 \mathrm{in}$.) from the interior surface of the OSB sheathing. Consistent with the OSB moisture content trends, walls without kraft facing exhibit significantly higher cavity RH levels.

Failure of some of the moisture sensors during the winter of 2011-2012 in Wall 8b prompted inspection of the interior cavity of that wall section. The gypsum board and insulation were removed in the summer of 2012. Inspection of the OSB and the framing members revealed water stains, mold growth, and corrosion of siding nails (Figure 8). These observations are consistent with high levels of relative humidity and OSB moisture content. The mold growth and corrosion developed between the time when the materials were installed new (November 2011) and the time when conditions dried out, likely mid-April 2012 by comparison to similar wall assemblies (Figures 6 and 7). Premature failure of the sensors' batteries may have been a result of persistent high RH levels. Because the sensors do not register moisture levels above the fiber saturation point, the actual moisture content in this wall configuration is unknown. The water staining suggests that OSB moisture content exceeded the fiber saturation point.
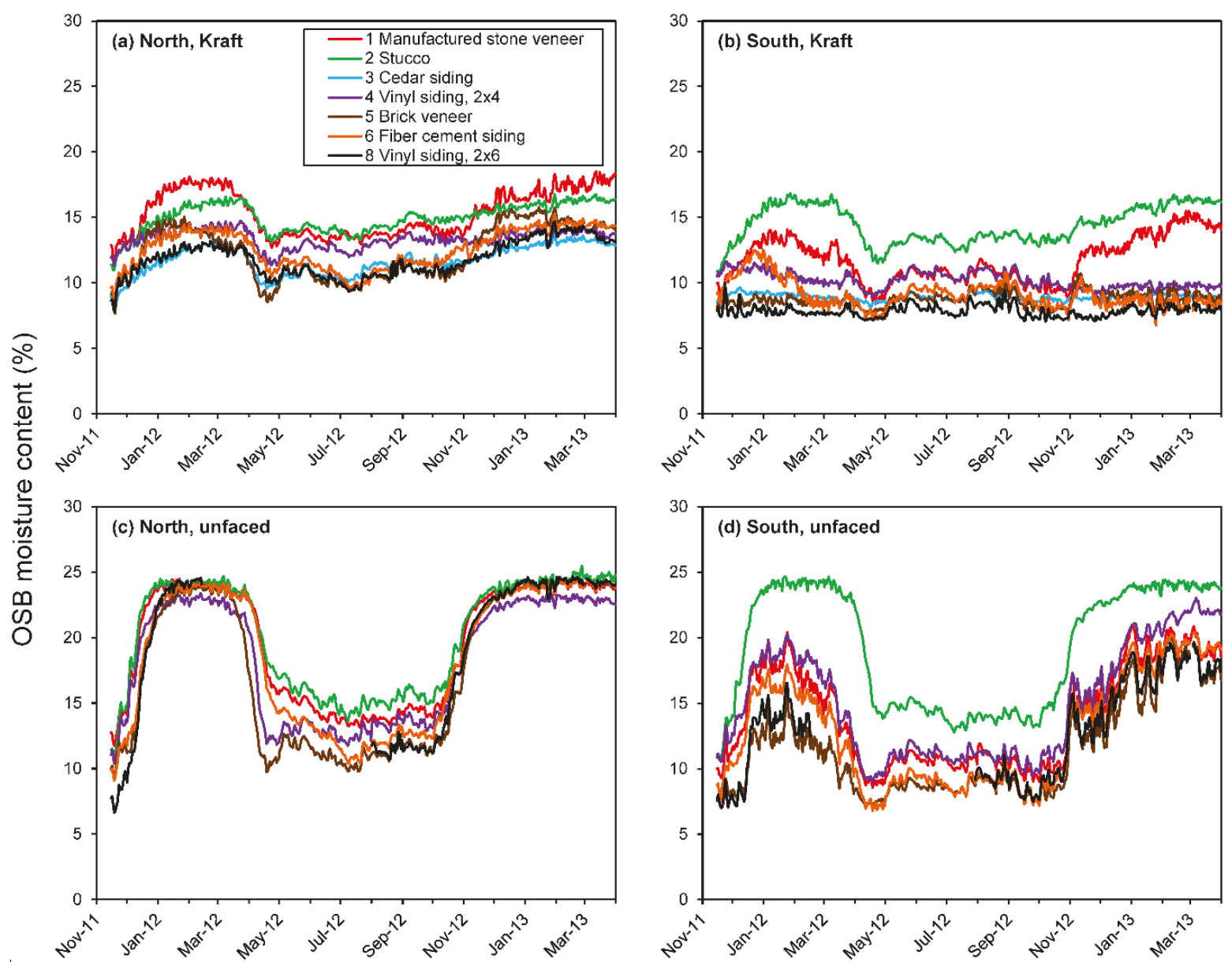

Figure 6. OSB moisture content measured in (a) North-facing walls with kraft-faced batts; (b) South-facing walls with kraft-faced batts; (c) North-facing walls with unfaced batts; and (d) South-facing walls with unfaced batts. 

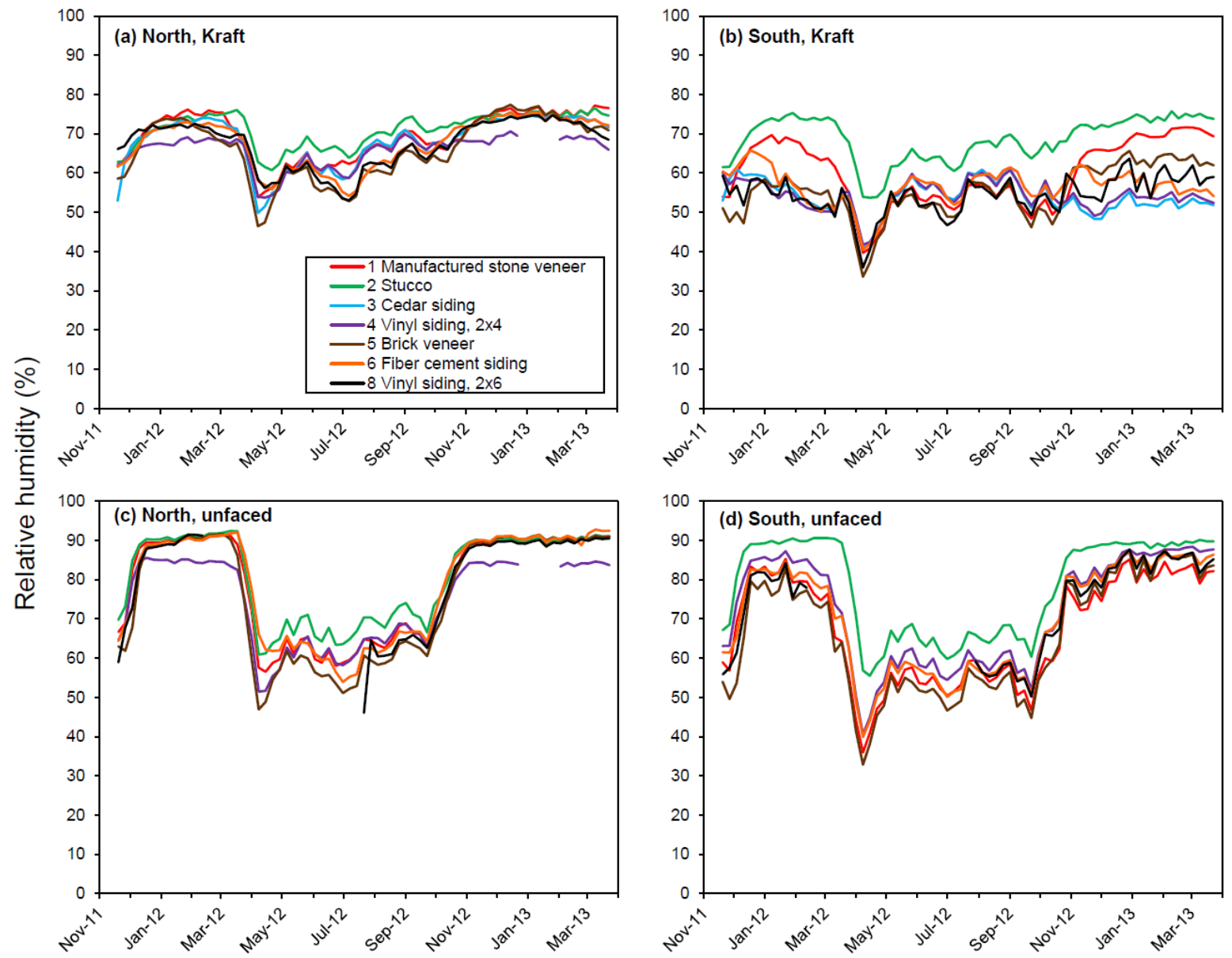

Figure 7. Relative humidity levels measured in cavities of (a) North-facing walls with kraft-faced batts; (b) South-facing walls with kraft-faced batts; (c) North-facing walls with unfaced batts; and (d) South-facing walls with unfaced batts.

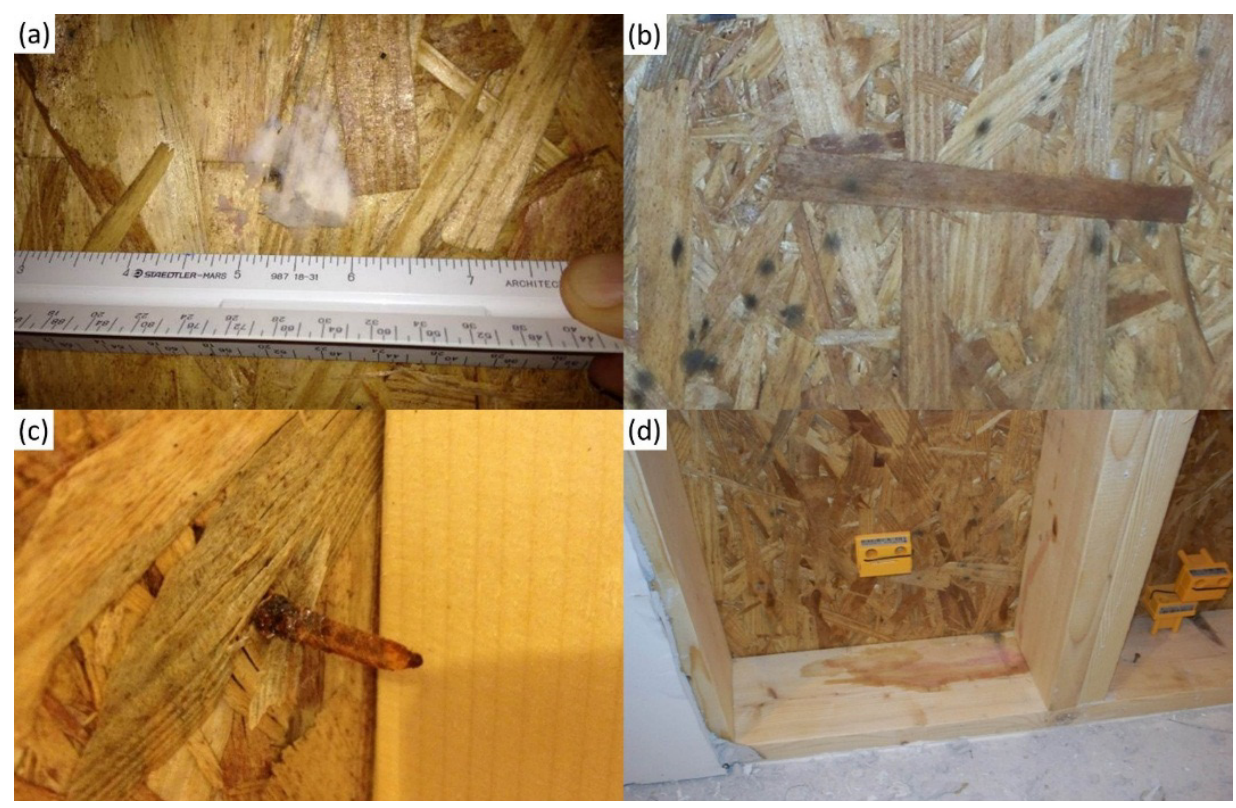

Figure 8. Observations indicating high moisture levels in the cavity of Wall 8b: $(\mathbf{a}, \mathbf{b})$ Mold growth; (c) Corrosion on siding nail; (d) Staining on bottom plate. 


\subsection{Effect of Exterior XPS Insulation on Wall Moisture Performance}

OSB moisture content is plotted in Figure 9 for walls with and without exterior extruded polystyrene insulation. All walls in this comparison included kraft facing as an interior vapor retarder. Wall 9 is configured similarly to Wall $4 \mathrm{a}(2 \times 4$ framing) but adds $25 \mathrm{~mm}(1 \mathrm{in}$.) XPS. Wall 7 is configured similarly to Wall $8 \mathrm{a}(2 \times 6$ framing) but adds $25 \mathrm{~mm}(1 \mathrm{in}$.) XPS. For the north exposure, Wall $9(2 \times 4$ with XPS) consistently had the lowest OSB moisture content. However, all six walls exhibited OSB moisture content below $15 \%$, and the difference between the walls was typically within a range of 3\% MC. Although Wall 4 started at a higher OSB moisture content and consistently remained at $2 \%-3 \% \mathrm{MC}$ higher than the other walls for nearly a year, during the second winter the gap became smaller, and the OSB moisture content in $2 \times 4$ and $2 \times 6$ walls without XPS became nearly identical. All six wall configurations showed a drying trend in the spring months. Interestingly, all walls showed a very similar drying rate as evidenced by the slopes of the moisture content curves; each wall showed a drop of about 2\% MC in April 2012. This behavior can be explained by the sharp drop in relative humidity in the cavity as a result of increasing cavity temperatures in the spring and the considerable drop in interior RH once humidifiers were turned off (Figure $2 b$ ).

For the South exposure, with exception of Configuration $4 \mathrm{a}(2 \times 4$ wall $)$ that had a higher initial moisture content, moisture levels in all walls oscillated within range of $7 \%-9 \% \mathrm{MC}$. Configuration $4 \mathrm{a}$ was roughly 3\% MC higher on average than the other walls during the first 12 months of the study. During the second heating season, Configuration $4 \mathrm{a}$ approached the range observed for the other walls.
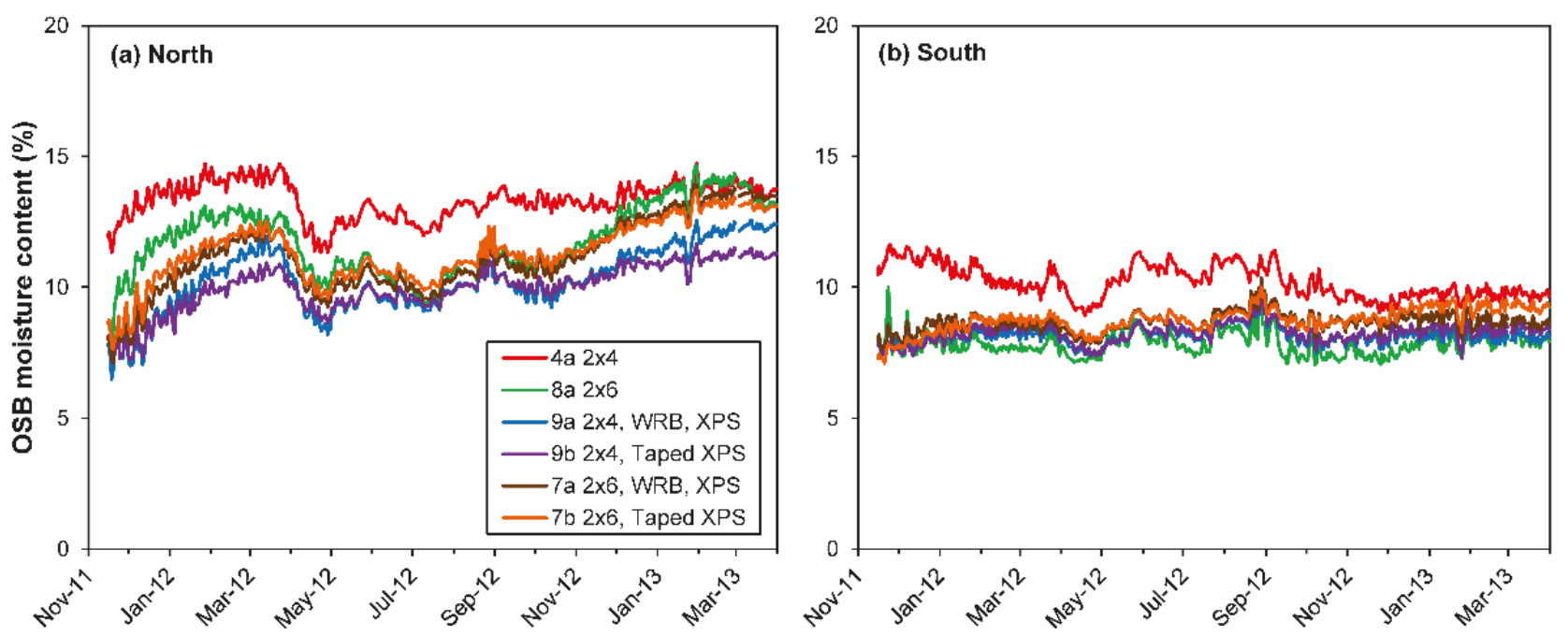

Figure 9. OSB moisture content in walls with and without exterior XPS insulation (all having an interior kraft vapor retarder): (a) North-facing walls; (b) South-facing walls.

A comparison of configurations with housewrap installed as a drainage plane versus those without housewrap but with taped XPS joints (\#7a vs. \#7b and \#9a vs. \#9b) shows a moisture content difference of less than $2 \% \mathrm{MC}$ in the winter months and less than $1 \% \mathrm{MC}$ in the summer months. Overall, the differences are not significant. It should be noted that this study does not address issues of drainage or drying related to the different installation practices. 
The impact of exterior XPS on cavity temperature and cavity relative humidity is shown in Figure 10 for north-facing walls (weekly averages are shown to smooth out daily fluctuations). There is a distinct trend in cavity temperature for all four walls in the winter months in a logical sequence from coldest to warmest: (i) $2 \times 6$ studs without XPS (Figure 8a); (ii) $2 \times 4$ studs without XPS (Figure 4a); (iii) $2 \times 6$ studs with XPS (Figure 7a); and (iv) $2 \times 4$ studs with XPS (Figure 9a). The difference in cavity temperatures was greatest during the month of January for both heating seasons, with a maximum difference of $6{ }^{\circ} \mathrm{C}$ (Figure 10). The observed cavity relative humidity levels show an approximate $20 \% \mathrm{RH}$ increase during the winter months relative to the summer months, but the different wall configurations do not follow a consistent trend.

In summary, $25 \mathrm{~mm}$ ( 1 in.) XPS exterior rigid insulation had a predictable impact on cavity temperature but marginal impact on cavity RH levels and moisture content of OSB sheathing in $2 \times 4$ and $2 \times 6$ walls with vinyl siding and interior kraft vapor retarder. OSB sheathing dried slightly in the spring at a similar rate regardless of whether or not walls included exterior XPS.
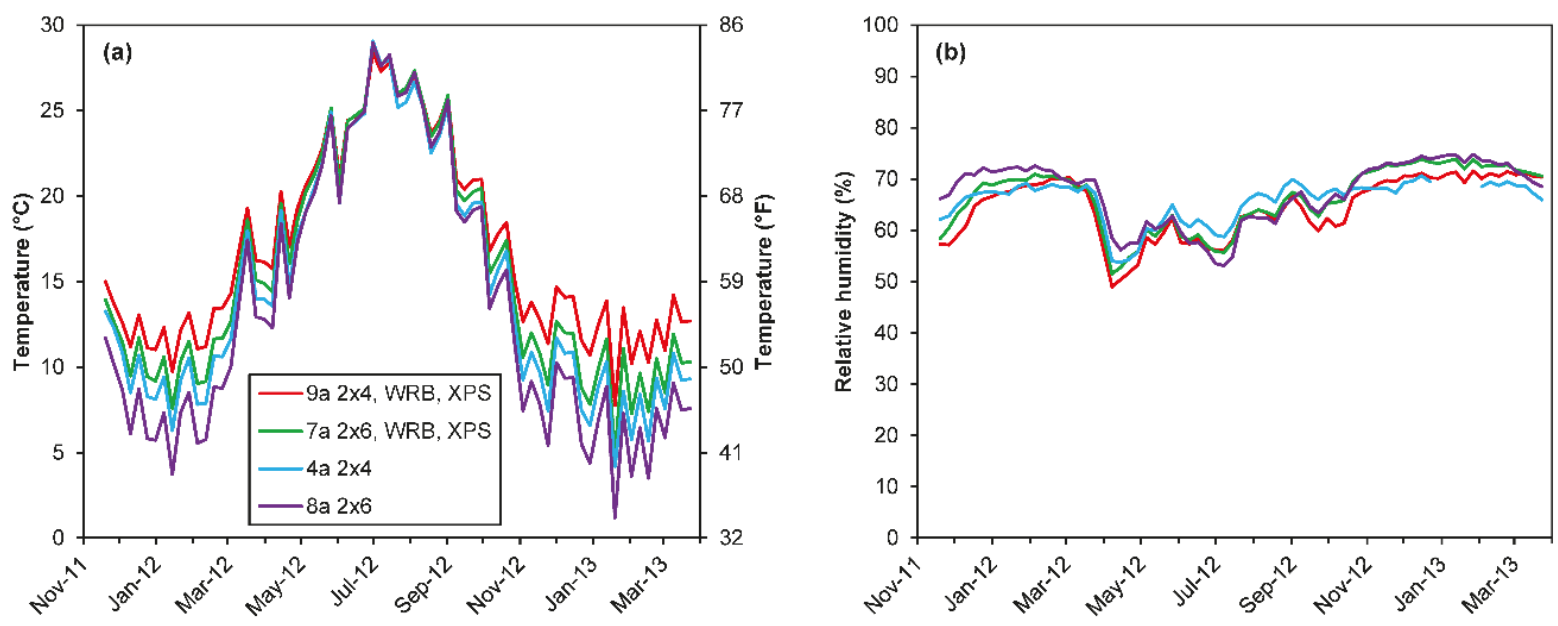

Figure 10. (a) Cavity temperatures in north-facing walls with and without exterior XPS insulation; (b) Cavity relative humidity levels in same walls.

\section{Hygrothermal Simulation Approach}

The test wall assemblies described above were simulated using WUFI ${ }^{\circledR}$ Pro 5.2 Software (Fraunhofer Insitute for Building Physics, Holzkirchen, Germany) for one-dimensional transient heat and moisture transfer [38,39] ("WUFI" stands for wärme und feuchtetransport instationär, German for "transient heat and moisture transport"). This software has been used extensively in North America for simulation of wood-frame wall assemblies [18,36,40-47]. One-dimensional hygrothermal simulations are often used by practitioners in North America for building envelope design analysis. In such cases actual material properties are not known with precision ahead of time, and practitioners rely on material properties from the literature or databases incorporated into simulation software. One objective of running these simulations was to evaluate the ability of the hygrothermal simulations to capture the observed differences between north- and south-facing walls and between walls with and without a kraft vapor retarder, particularly with elevated indoor humidity levels during winter using mainly generic material properties. Measured interior and exterior conditions and some select 
measured material properties were used as available. This was not a model validation exercise because the project scope did not allow for full measurement of all model input parameters. A second objective of running the simulations was to investigate the reliability of interior latex primer and paint on gypsum board for vapor diffusion control in this climate. Model parameters are described below.

\subsection{Wall Configurations}

Wall configurations are listed in Table 1. Each configuration was modeled as a multi-layer assembly, taking a one-dimensional section through the insulated cavity (rather than the framing). Each configuration was simulated in both north-facing and south-facing orientations.

\subsection{Material Properties}

Material properties for most materials were assigned from the WUFI North America Database [38]. Many of the properties in this database are taken from the work of Kumaran et al. [9]. Property values used in the simulations are tabulated in the Supplementary Materials. Certain material properties were adjusted based on measured values (Table 2) as indicated in the Supplementary Materials.

Interior primer and paint layers on gypsum board were modeled as an interior surface diffusion resistance based on measured permeance values. Exterior primer and paint layers on cedar siding and fiber cement siding were modeled as a single layer having an RH-dependent vapor permeance curve calculated from the difference between measurements on uncoated cedar and cedar with exterior primer and paint (Table 2).

Thermal resistance values of insulation materials in the simulations were equivalent to typical nominal values at $24{ }^{\circ} \mathrm{C}\left(75^{\circ} \mathrm{F}\right)$. R-values of glass fiber insulation were $2.3 \mathrm{~m}^{2} \cdot \mathrm{K} / \mathrm{W}\left(13 \mathrm{~h} \cdot \mathrm{ft}^{2} \cdot{ }^{\circ} \mathrm{F} / \mathrm{Btu}\right)$ for $89 \mathrm{~mm}$ (3.5 in.) thickness and $3.7 \mathrm{~m}^{2} \cdot \mathrm{K} / \mathrm{W}\left(21 \mathrm{~h} \cdot \mathrm{ft}^{2} \cdot{ }^{\circ} \mathrm{F} / \mathrm{Btu}\right)$ for $140 \mathrm{~mm}(5.5 \mathrm{in}$.$) thickness.$ R-value of extruded polystyrene was $0.9 \mathrm{~m}^{2} \cdot \mathrm{K} / \mathrm{W}\left(5 \mathrm{~h} \cdot \mathrm{ft}^{2} \cdot{ }^{\circ} \mathrm{F} / \mathrm{Btu}\right)$ at $25 \mathrm{~mm}(0.98 \mathrm{in}$.) thickness.

\subsection{Initial Conditions}

The initial moisture content of OSB was set to correspond with measured values in each of the wall assemblies. For materials other than OSB, the initial moisture content was set at equilibrium with $65 \%$ $\mathrm{RH}$. Initial temperature in all materials was set to $21^{\circ} \mathrm{C}\left(70^{\circ} \mathrm{F}\right)$.

\subsection{Interior and Exterior Conditions}

Interior and exterior conditions were taken from onsite measurements (Section 2.2) with the exception of rainfall data. The onsite data were collected at half-hour intervals and were averaged to obtain hourly values. Hourly rainfall data were obtained from the nearest weather station, Andrews Air Force Base. Wind-driven rain on the walls was calculated according to ASHRAE Standard 160 [27], using measured horizontal rainfall, wind speed, and wind direction. A rain exposure factor of 1.0

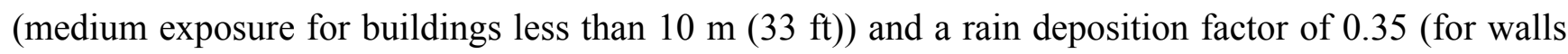
below a steep-slope roof) were assumed. 


\subsection{Surface Transfer Coefficients}

The exterior surface heat transfer coefficient was the sum of a radiative component $\left(6.5 \mathrm{~W} /\left(\mathrm{m}^{2} \cdot \mathrm{K}\right)\right)$, a convective constant $\left(4.5 \mathrm{~W} /\left(\mathrm{m}^{2} \cdot \mathrm{K}\right)\right)$, and the product of the wind velocity and a coefficient $\left(1.6 \mathrm{~W} \cdot \mathrm{s} /\left(\mathrm{m}^{3} \cdot \mathrm{K}\right)\right.$ for windward conditions and $0.33 \mathrm{~W} \cdot \mathrm{s} /\left(\mathrm{m}^{3} \cdot \mathrm{K}\right)$ for leeward conditions $)$. Standard values were used for short-wave radiation absorptivity and long-wave radiation emissivity (depending on the cladding type). Standard values were used for the adhering fraction of rain (0.7) and the interior surface heat transfer resistance $\left(0.125 \mathrm{~m}^{2} \cdot \mathrm{K} / \mathrm{W}\right)$. Cavity ventilation was simulated only for brick veneer with a constant air exchange rate of $2 \mathrm{~h}^{-1}$ in the $25 \mathrm{~mm}$ (1 in.) air cavity.

\subsection{Simulation Period and Numerical Parameters}

Simulations had a start date corresponding to 1 December, 2011, a one-hour time step, and an end date corresponding to $31 \mathrm{March}, 2013$. Default values were used for numerical calculation parameters except that adaptive time step control was enabled, which in combination with a fine numerical grid minimized convergence failures.

\section{Hygrothermal Simulation Results and Discussion}

Measured OSB moisture contents from the north-facing test walls are compared with simulated values in Figure 11. In general, the simulations correctly predicted the seasonal trends in OSB moisture content and the differences between walls with and without kraft vapor retarders. However, the simulations often differed considerably from measured values. Fair to good agreement between measured and simulated values was found for several assemblies with interior kraft facing (Figure 11c,e-i). The maximum differences between measured and simulated values were $2.5 \% \mathrm{MC}$ (Figure 11c); $4.5 \%$ (Figure 11e); 3.1\% (Figure 11f); 3.8\% (Figure 11g); 4.2\% (Figure 11h); and 3.2\% (Figure 11i). The root-mean-square errors (RMSEs) for these assemblies were $2.1 \% \mathrm{MC}$ or less. In contrast, simulated OSB moisture contents in walls with a kraft vapor retarder and either manufactured stone veneer (Figure 11a) or stucco (Figure 11b) were significantly lower than measured values, the differences being as large as 7\% MC. Large under-prediction (almost $6 \% \mathrm{MC}$ ) was also seen for the $2 \times 4$ wall with vinyl siding (Figure 11d).

The largest apparent discrepancies between measured and simulated values were observed for north-facing walls without a kraft vapor retarder during winter months. The y-axis in Figure 11 is limited to $30 \% \mathrm{MC}$, but simulated values in some cases exceeded $60 \% \mathrm{MC}$ as a result of vapor diffusion, given the high interior humidity levels and the high vapor permeance of painted gypsum. As mentioned previously, the sensors were not capable of determining moisture content above approximately 25\% MC (i.e., sensors read 25\% MC even if the actual moisture content was higher). Therefore, meaningful comparisons between measured and simulated moisture levels cannot be made in this range. However, simulations approximately predicted the duration of excessive OSB moisture content during winter, though simulated values tended to lag behind the measured values when the OSB MC increased sharply in fall/winter and decreased rapidly in spring. 

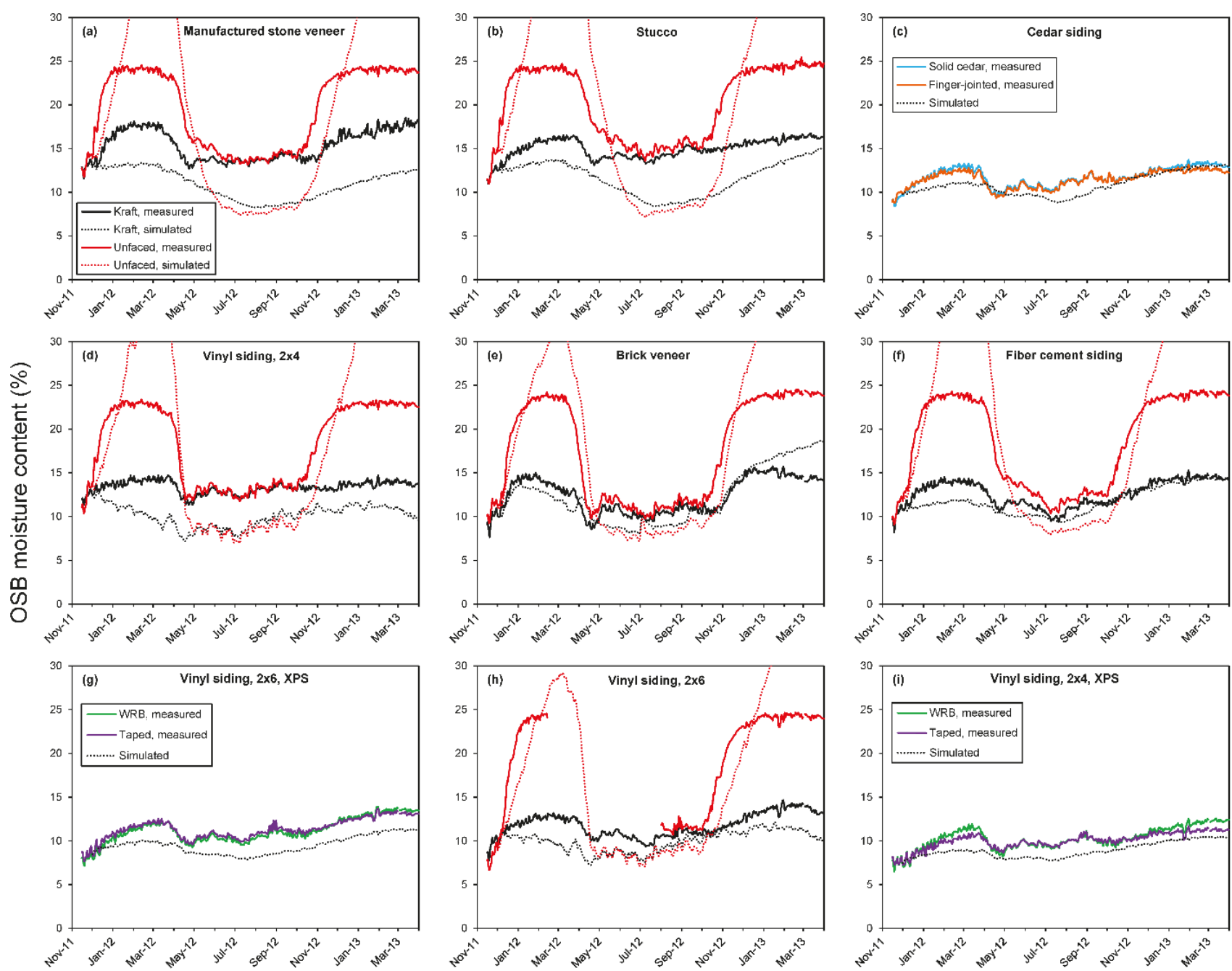

Figure 11. Measured and simulated OSB moisture content in north-facing walls.

Measured and simulated values for south-facing walls are compared in Figure 12. Several walls with a kraft vapor retarder again showed good agreement, with maximum differences of 3.7\% $\mathrm{MC}$ (Figure 12c); 3.6\% (Figure 12d); 3.0\% (Figure 12e); 2.5\% (Figure 12g); 2.1\% (Figure 12h); and 1.9\% (Figure 12i). The RMSEs for these assemblies were $2.1 \%$ MC or less. In contrast, simulated OSB moisture contents in walls with a kraft vapor retarder and either manufactured stone veneer (Figure 12a) or stucco cladding (Figure 12b) were significantly lower than measured values, the differences being as large as $7 \% \mathrm{MC}$, similar to the corresponding north-facing walls.

In general, measured OSB moisture content in walls without interior kraft facing had a lower winter peak in the south orientation relative to the north orientation. This trend was captured by the simulations, though significant over-prediction was seen in a few instances, particularly in February to March 2013 (Figure $12 \mathrm{~b}, \mathrm{~d}, \mathrm{f}, \mathrm{h}$ ). In walls without a kraft vapor retarder with either manufactured stone veneer or stucco cladding, the simulations under-predicted OSB MC during summer by up to $7 \% \mathrm{MC}$ in south-facing walls (Figure 12a,b).

The discrepancies between measured and simulated OSB moisture contents discussed above may stem from several sources. Previous research has shown that simulation results may depend strongly on material properties [48]. In this case, the liquid diffusivity and moisture retention properties of absorptive claddings like stucco and manufactured stone veneer may be important; these were not 
measured in this study. In addition, air leakage within wall assemblies can contribute to wetting and drying but was not included in simulations because airflow is very difficult to predict and the air permeance of the test wall sections was not tested. Measurement error in OSB moisture content could come from calibration uncertainty (about $2 \% \mathrm{MC}$ ) or error in temperature compensation (likely less than $1 \% \mathrm{MC}$ ). In addition, the moisture sensors in this study displaced insulation in the wall cavities, whereas the simulations assumed the cavities were fully insulated. The sensors also used bare stainless steel screws as electrodes, which read the highest moisture content through the OSB thickness, whereas the simulation output was average moisture content across the OSB layer.
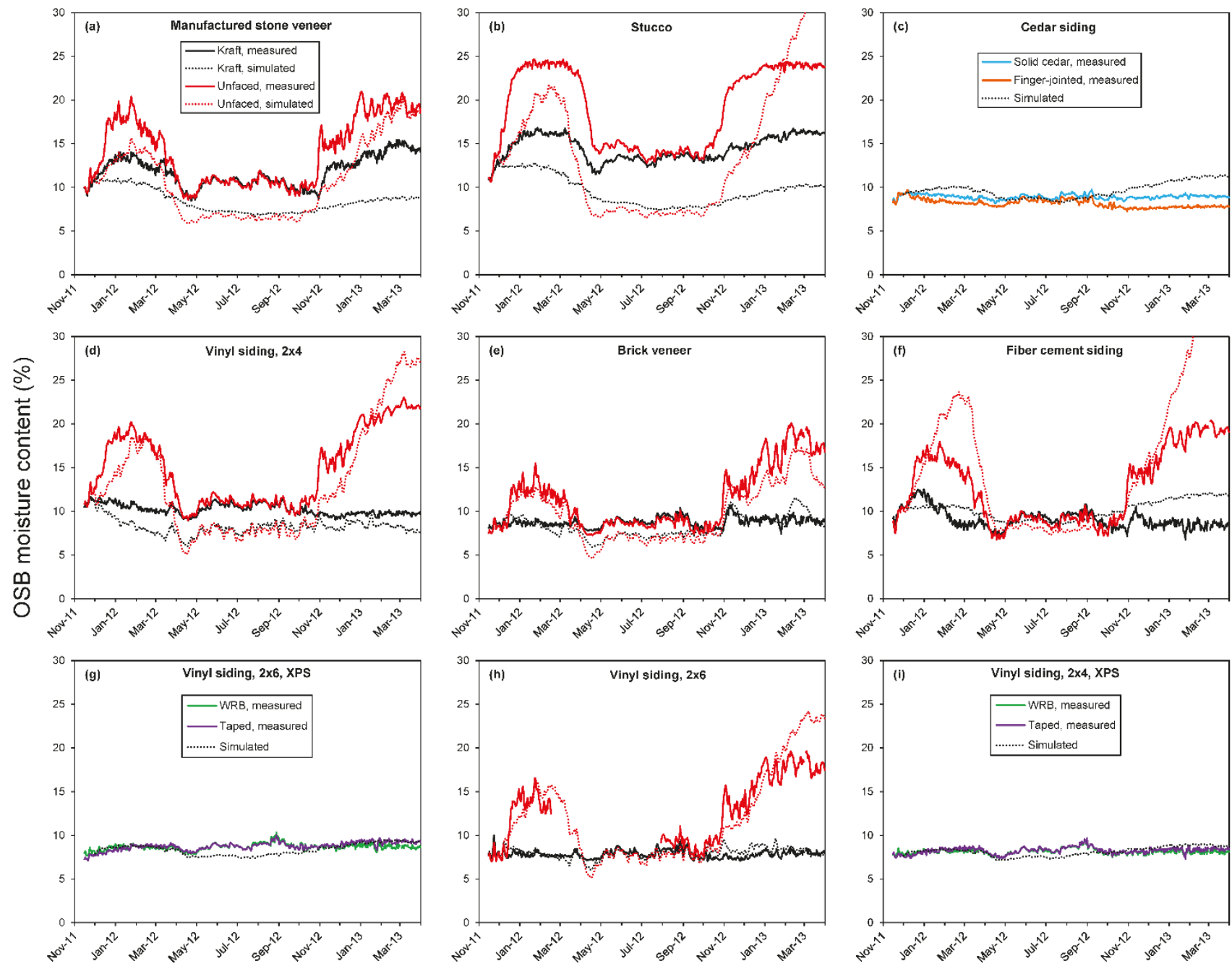

Figure 12. Measured and simulated OSB moisture content in south-facing walls.

The simulation results here for assemblies that rely on interior gypsum board with latex primer and paint can be compared with previous simulations for similar mixed-humid climate locations (Table 3). Together these simulations give a consistent picture of the sensitivity of north-facing walls to moisture accumulation with increasing interior humidity and interior vapor permeance. 
Table 3. Comparison of hygrothermal simulations.

\begin{tabular}{cccc}
\hline \multirow{2}{*}{ Reference } & Wintertime Interior RH & $\begin{array}{c}\text { Interior Vapor Permeance, } \\
\mathbf{n g} /\left(\mathbf{P a} \cdot \mathbf{s} \cdot \mathbf{m}^{2}\right) \text { (perms) }\end{array}$ & $\begin{array}{c}\text { Peak OSB } \\
\text { Moisture Content }\end{array}$ \\
\hline This work & $55 \%$ & $2000(35)$ & $>30 \%$ (north-facing) \\
\hline \multirow{2}{*}{ Karagiozis et al. [6] } & $\begin{array}{c}\text { "high" } \\
\text { "low" }\end{array}$ & $460(8)$ & $18 \%-25 \%$ \\
& $35 \%$ & $570(10)$ & $16 \%$ (north-facing) \\
\hline \multirow{2}{*}{ Glass [36] } & $45 \%$ & $290(5)$ & $17 \%$ (north-facing) \\
& $45 \%$ & $570(10)$ & $22 \%$ (north-facing) \\
& $45 \%$ & $1100(20)$ & $27 \%$ (north-facing) \\
\hline
\end{tabular}

\section{Conclusions}

Measurements in exterior walls of two test structures located near Washington, DC (IECC Climate Zone 4A) showed that north-facing walls generally reached higher OSB moisture contents than south-facing walls in winter, and all walls dried out in spring. The combination of high interior humidity and high vapor permeance of painted gypsum board led to significant moisture accumulation in exterior OSB sheathing during winter in walls without a vapor retarder. Laboratory measurements indicated that the vapor permeance of gypsum board with latex primer and paint was considerably higher than other measurements and the value assumed by the IRC. Inspection of a wall in which sensors had failed revealed water stains, mold growth, and corrosion of siding nails. In contrast, wintertime moisture accumulation was not significant in walls with an interior kraft vapor retarder. XPS exterior rigid insulation of $25 \mathrm{~mm}$ ( $1 \mathrm{in}$.) thickness had a predictable effect on wall cavity temperature but a marginal impact on cavity RH levels and OSB moisture content in walls with vinyl siding and interior kraft vapor retarder.

Simulations with a one-dimensional hygrothermal model using measured interior and exterior conditions and some select measured material properties approximately captured the timing of seasonal increases and decreases in OSB moisture content, the differences between north- and south-facing walls, and the differences between walls with and without an interior kraft vapor retarder. Agreement between simulation and measurement was fair to good in many cases. However, simulated OSB moisture contents tended to be considerably lower than measured values during summer, particularly for walls clad with manufactured stone veneer and stucco. The $25 \% \mathrm{MC}$ limit of the moisture sensors precluded meaningful comparisons above this level, which occurred consistently for north-facing walls without a kraft vapor retarder during winter months.

The impact of air leakage on wetting and drying was not assessed in this project. Further research is needed to uncouple the effects of air leakage from vapor diffusion. The interior humidity levels maintained in the test structures were based on ASHRAE Standard 160 [27], simplified method, and led to sheathing moisture contents in wall assemblies with interior latex primer/paint as the only vapor retarder that were considerably higher than those measured in occupied single-family homes in the same climate zone. Further research is needed to evaluate the appropriateness of this method for indoor humidity and the reliability of interior latex primer/paint to serve as a Class III vapor retarder. 


\section{Supplementary Materials}

Supplementary materials can be accessed at: http://www.mdpi.com/2075-5309/5/3/759/s1.

\section{Acknowledgments}

This work was funded by the U.S. Forest Service Forest Products Laboratory and the NAHB Research Center (now Home Innovation Research Labs) through Joint Venture Agreements 11-JV-11111133-074 and 12-JV-11111136-070.

\section{Author Contributions}

This article is based on a project final report. Vladimir Kochkin, S. Craig Drumheller, and Samuel V. Glass designed the study; S. Craig Drumheller and Lance Barta installed sensors in test structures and performed laboratory measurements; Vladimir Kochkin and Lance Barta analyzed the data and wrote the project final report; Samuel V. Glass carried out hygrothermal simulations and prepared this article.

\section{Conflicts of Interest}

The authors declare no conflict of interest.

\section{References}

1. International Code Council. International Energy Conservation Code; International Code Council: Country Club Hills, IL, USA, 2012.

2. International Code Council. International Energy Conservation Code; International Code Council: Country Club Hills, IL, USA, 2009.

3. Lstiburek, J.W. Understanding vapor barriers. ASHRAE J. 2004, 46, 40-47.

4. U.S. Department of Energy. Climate Zones. Available online: http://energy.gov/eere/buildings/ climate-zones (accessed on 1 April 2015).

5. International Code Council. International Residential Code for One- and Two-Family Dwellings; International Code Council: Country Club Hills, IL, USA, 2009.

6. Karagiozis, A.N.; Lstiburek, J.; Desjarlais, A. Scientific Analysis of Vapor Retarder Recommendations for Wall Systems Constructed in North America. In Proceedings of the Thermal Performance of the Exterior Envelopes of Whole Buildings XI International Conference, Clearwater Beach, FL, USA, 5-9 December 2010.

7. Carll, C.G.; Highley, T.L. Decay of wood and wood-based products above ground in buildings. J. Test. Eval. 1999, 27, 150-158.

8. American Society of Heating, Refrigerating and Air-Conditioning Engineers, Inc. (ASHRAE). 2013 ASHRAE Handbook—Fundamentals; ASHRAE: Atlanta, GA, USA, 2013. 
9. Kumaran, M.K.; Lackey, J.C.; Normandin, N.; Tariku, F.; van Reenen, D. A Thermal and Moisture Transport Property Database for Common Building and Insulating Materials: Final Report from ASHRAE Research Project 1018-RP; American Society of Heating, Refrigerating and Air-Conditioning Engineers, Inc.: Atlanta, GA, USA, 2002.

10. Martin, P.C.; Verschoor, J.D. Investigation of Water Vapor Migration and Moisture Storage in an Insulated Wall Structure: Final Report from ASHRAE Research Project 496-RP; American Society of Heating, Refrigerating and Air-Conditioning Engineers, Inc.: Atlanta, GA, USA, 1994.

11. Manufactured Housing Research Alliance. Measured Permeance Values for Selected Interior Wall Assemblies. Available online: http:/www.research-alliance.org/pages/perm.htm (accessed on 24 April 2015).

12. Drumheller, S.C.; Carll, C.G. Effect of Cladding Systems on Moisture Performance of Wood-Framed Walls in a Mixed-Humid Climate. In Proceedings of Thermal Performance of the Exterior Envelopes of Whole Buildings XI International Conference, Clearwater Beach, FL, USA, 5-9 December 2010.

13. Wilson, A.G. CBD-23. Air Leakage in Buildings; National Research Council of Canada: Ottawa, Canada, 1961.

14. TenWolde, A.; Rose, W.B. Moisture control strategies for the building envelope. J. Therm. Insul. Build. Envel. 1996, 19, 206-214.

15. Straube, J.F.; Burnett, E.F.P. Building Science for Building Enclosures; Building Science Press: Westford, MA, USA, 2005; p. 549.

16. Glass, S.V.; TenWolde, A. Review of In-Service Moisture and Temperature Conditions in Wood-Frame Buildings; U.S. Department of Agriculture, Forest Service, Forest Products Laboratory: Madison, WI, USA, 2007.

17. Maref, W.; Armstrong, M.M.; Rousseau, M.Z.; Lei, W. A Field Monitoring Investigation of the Effect of Adding Different Exterior Thermal Insulation Materials on the Hygrothermal Response of Wood-Frame Walls in a Cold Climate. In Proceedings of the Building Enclosure Science \& Technology (BEST2) Conference, Portland, OR, USA, 12-14 April 2010.

18. Arena, L.B.; Owens, D.; Mantha, P. Measured Performance of an R-40 Double-Stud Wall in Climate Zone 5a. In Proceedings of the Thermal Performance of the Exterior Envelopes of Whole Buildings XII International Conference, Clearwater Beach, FL, USA, 1-5 December 2013.

19. Parsons, G.; Lieburn, B. Comparative Energy and Wall Performance of Twelve Residential Houses Constructed in a Cold Climate. In Proceedings of the Thermal Performance of the Exterior Envelopes of Whole Buildings XII International Conference, Clearwater Beach, FL, USA, 1-5 December 2013.

20. Craven, C.; Garber-Slaght, R. Exterior insulation envelope retrofits in cold climates: Implications for moisture control. HVAC\&R Res. 2014, 20, 384-394.

21. Fox, M.; Straube, J.; Ge, H.; Trainor, T. Field Test of Hygrothermal Performance of Highly Insulated Wall Assemblies. In Proceedings of the 14th Canadian Conference on Building Science and Technology, Toronto, Canada, 28-30 October 2014; pp. 101-110.

22. Ueno, K. Monitoring of Double-Stud Wall Moisture Conditions in the Northeast; Building America Report 1501; Building Science Corporation: Westford, MA, USA, 2015. 
23. Smegal, J.; Lstiburek, J.; Straube, J.; Grin, A. Moisture-Related Durability of Walls with Exterior Insulation in the Pacific Northwest. In Proceedings of the Thermal Performance of the Exterior Envelopes of Whole Buildings XII International Conference, Clearwater Beach, FL, USA, 1-5 December 2013.

24. Home Innovation Research Labs. Moisture Performance of Walls in Energy Efficient Homes; Home Innovation Research Labs: Upper Marlboro, MD, USA, 2014.

25. NAHB Research Center. Moisture Performance of Wood-Based Sheathing on Exterior Walls Clad with Absorptive Materials; NAHB Research Center: Upper Marlboro, MD, USA, 2010.

26. NAHB Research Center. Moisture Performance of Wall Systems with Increased Indoor Relative Humidity (Phase II Analysis); NAHB Research Center: Upper Marlboro, MD, USA, 2011.

27. American Society of Heating, Refrigerating and Air-Conditioning Engineers, Inc. (ASHRAE). ANSI/ASHRAE Standard 160-2009, Criteria for Moisture-Control Design Analysis in Buildings; ASHRAE: Atlanta, GA, USA, 2009.

28. Antretter, F.; Karagiozis, A.; Holm, A.; Glass, S. Interior Temperature and Relative Humidity Distributions in Mixed-Humid and Cold Climates as Building Simulation Boundary Conditions. In Proceedings of the Thermal Performance of the Exterior Envelopes of Whole Buildings XI International Conference, Clearwater Beach, FL, USA, 5-9 December 2010.

29. TenWolde, A.; Walker, I.S. Interior Moisture Design Loads for Residences. In Proceedings of the Performance of Exterior Envelopes of Whole Buildings VIII International Conference, Clearwater Beach, FL, USA, 2-7 December 2001.

30. ASTM International. ASTM D226/D226M-09, Standard Specification for Asphalt-Saturated Organic Felt Used in Roofing and Waterproofing; ASTM International: West Conshohocken, PA, USA, 2009.

31. U.S. Census Bureau. Principal Type of Exterior Wall Material of New Single-Family Houses Completed. Available online: http:/www.census.gov/const/C25Ann/sftotalexwallmat.pdf (accessed on 2 April 2015).

32. ASTM International. ASTM E96/E96M-10, Standard Test Methods for Water Vapor Transmission of Materials; ASTM International: West Conshohocken, PA, USA, 2010.

33. ASTM International. ASTM D2395-07, Standard Test Methods for Specific Gravity of Wood and Wood-Based Materials; ASTM International: West Conshohocken, PA, USA, 2007.

34. Gatland, S. Comparison of Water Vapor Permeance Data of Common Interior Building Materials in North American Wall Systems. In Proceedings of the 10th Canadian Conference on Building Science and Technology, Ottawa, Canada, 12-13 May 2005; pp. 182-194.

35. Burch, D.M.; Thomas, W.C.; Fanney, A.H. Water vapor permeability measurements of common building materials. ASHRAE Trans. 1992, 98, 486-494.

36. Glass, S.V. Hygrothermal Analysis of Wood-Frame Wall Assemblies in a Mixed-Humid Climate; U.S. Department of Agriculture, Forest Service, Forest Products Laboratory: Madison, WI, USA, 2013.

37. James, W.L. Electric Moisture Meters for Wood; U.S. Department of Agriculture, Forest Service, Forest Products Laboratory: Madison, WI, USA, 1988.

38. Fraunhofer Institute for Building Physics. WUFI ${ }^{\circledR}$ Pro, 5.2; Fraunhofer Institute for Building Physics: Holzkirchen, Germany, 2013. 
39. Künzel, H.M.; Kiessl, K. Calculation of heat and moisture transfer in exposed building components. Int. J. Heat Mass Transf. 1997, 40, 159-167.

40. Trechsel, H.R. Moisture Analysis and Condensation Control in Building Envelopes; American Society for Testing and Materials: West Conshohocken, PA, USA, 2001.

41. Karagiozis, A.; Künzel, H.; Holm, A. WUFI-ORNL/IBP-A North American Hygrothermal Model. In Proceedings of the Performance of Exterior Envelopes of Whole Buildings VIII International Conference, Clearwater Beach, FL, USA, 2-7 December 2001.

42. Finch, G.; Straube, J. Ventilated Wall Claddings: Review, Field Performance, and Hygrothermal Modeling. In Proceedings of the Thermal Performance of the Exterior Envelopes of Whole Buildings X International Conference, Clearwater Beach, FL, USA, 2-7 December 2007.

43. Straube, J.; Smegal, J. Building America Special Research Project: High-R Walls Case Study Analysis; Building Science Corporation: Somerville, MA, USA, 2009.

44. Yuan, S.; Karagiozis, A.N. The Hygrothermal Performance of Wood-Framed Wall Systems Using Spray Polyurethane Foam Insulations and a Smart Vapor Retarder in the Pacific Northwest. In Proceedings of the Thermal Performance of the Exterior Envelopes of Whole Buildings XI International Conference, Clearwater Beach, FL, USA, 5-9 December 2010.

45. Pazera, M.; Salonvaara, M. Drying characteristics of spray-applied cellulose fiber insulation. J. Test. Eval. 2011, 39, 219-229.

46. Weston, T.A.; Minnich, L.C. Moisture measurements and condensation potential in wood frame walls in a hot-humid climate. J. Test. Eval. 2011, 39, 395-409.

47. Lepage, R.; Schumacher, C.; Lukachko, A. Moisture management for High R-Value Walls; Building Science Corporation: Somerville, MA, USA, 2013.

48. Karagiozis, A. Application of Advanced Tools to Develop Energy Efficient Building Envelopes that Are Durable. In Proceedings of the Performance of Exterior Envelopes of Whole Buildings IX International Conference, Clearwater Beach, FL, USA, 5-10 December 2004.

(C) 2015 by the authors; licensee MDPI, Basel, Switzerland. This article is an open access article distributed under the terms and conditions of the Creative Commons Attribution license (http://creativecommons.org/licenses/by/4.0/). 